\title{
Características da clientela residente em setores sociais periféricos que demanda assistência em planejamento familiar
}

\author{
Eleonor Moretti ${ }^{1}$ \\ Leila Ibrahim Hoffmann ${ }^{2}$ \\ Marilan Piva ${ }^{2}$ \\ Silvia Regina Rossetto ${ }^{2}$ \\ Rosane Schneider ${ }^{2}$
}

\section{RESUMO}

Este trabalho apresenta o estudo das características da clientela residente em setores sociais periféricos que demanda assistência em planejamento familiar.

A primeira parte do trabalho apresenta (30) trinta tabelas que demonstram as características das mulheres entrevistas. As 7 (sete) tabelas seguintes analisam características pessoais das clientes relacionadas entre si.

Esta verificação foi possibilitada pela aplicação de um formulário em 96 mulheres, que estavam em suas residências na ocasião da coleta de dados.

O tratamento estatístico e a análise dos dados foram efetuados a partir de porcentagem e das hipóteses estatísticas e teste de significância

1. Ginecologista.

2. Acadêmicas. 
"qui-qua-drado" ao nível de 0,05 entre as variáveis dependentes e independentes e foram obtidos os seguintes resultados:

Não existe associação significante, ao nível de 0,05 , comparando:

- o hábito de fumar das clientes com a presença de hipertensão arterial;

- o hábito de fumar das clientes com a presença de obesidade;

- a idade das clientes com o hábito de fumar;

- a idade das clientes com a presença de hipertensão arterial;

- a idade das clientes com a presença de obesidade;

- o estado civil das clientes e com quem elas residem;

- o planejamento familiar com a idade das clientes.

Conclui-se que os resultados obtidos neste trabalho são de grande utilidade como subsídios para o planejamento de ações de saúde da mulher dentro de uma nova e atual abordagem de assistência em planejamento familiar.

\section{FINALIDADE}

Melhoria do ensino, pesquisa e assistência de saúde em planejamento familiar à clientele do município de Passo Fundo e região.

\section{JUSTIFICATIVA E DEFINIÇÃO DO PROBLEMA}

Tendo por base a prática profissional e pesquisa anteriormente realizada, decidiu-se desenvolver este trabalho no intuito de ampliar a amostra a as variáveis estudadas.

Conforme resultados obtidos em estudo anterior recomendou-se: a) Oferecer programas de orientação e assistência em planejamento familiar em nossa comunidade; b) Ampliar e aprofundar os conteúdos de ensino e planejamento familiar nos Cursos de Enfermagem; c) Utilizar, ampliar e aprofundar as pesquisas de assistência de Enfermagem em Planejamento Familiar.

Este trabalho, foi fruto do exercício da profissão junto à clientele que demanda de assistência em planejamento familiar e do ensino das disciplina de Enfermagem Ginecológica e Obstétrica da UPF Portanto, considerando-se o exposto acima, formula-se o seguinte problema: quais as 
características da clientela residente em setores sociais periféricos que demanda assistência em Planejamento Familiar?

\section{OBJETIVOS}

\section{Objetivo Geral}

Identificar as características da clientela residente em setores sociais periféricos, que demanda assistência em Planejamento Familiar.

\section{Objetivos Específicos}

Assistencial: Oferecer programas de orientação e assistência em Planejamento Familiar em nossa comunidade.

Ensino:

a) Introduzir conteúdos novos de Planejamento Familiar.

b) Auxiliar e aprofundar os conteúdos de ensino e Planejamento Familiar nos Cursos de Enfermagem.

Pesquisa:

Utilizar, ampliar e aprofundar as pesquisas em Planejamento Familiar.

\section{HIPÓTESES}

Verifica-se na literatura consultada que o planejamento familiar é influenciado por características pessoais das clientes, sem grande instrução e nível sócio-econômico, bem como, por diversos fatores de risco, formulam-se as seguintes hipóteses: 


\section{H0}

1. Não existe associação significante, no nível de 0,05 , comparando o hábito de fumar das clientes com a presença de hipertensão arterial.

2. Não existe associação significante, no nível de 0,05 , comparando o hábito de fumar das clientes com a presença de obesidade.

3. Não existe associação sïgnificante, no nível de 0,05 , comparando a idade das clientes com o hábito de fumar.

4. Não existe associação significante, no nível de 0,05 , comparando a idade das clientes com a presença de hipertensão arterial.

5. Não existe associação significante, no nível de 0,05 , comparando a idade das clientes com a presença de obesidade.

6. Não existe associação significante, no nível de 0,05 , comparando o estado civil das clientes com quem elas residem.

7. Não existe associação significante, no nível de 0,05 , comparando o planejamento familiar e o não planejamento com a idade das clientes.

\section{H1}

1. Existe associação significante, no nível de 0,05, comparando o hábito de fumar das clientes com; a presença de hipertensão arterial,

2. Existe associação significante, no nível de 0,05, comparando o hábito de fumar das clientes com a presença de obesidade.

3. Existe associação significante, no nível de 0,05 , comparando a idade das clientes com o hábito de fumar.

4. Existe associação significante, no nível de $0,0.5$, comparando a idade, das clientes com a presença de hipertensão arterial.

5. Existe associação significante, no nível de 0,05, comparando a idade das clientes com a presença de obesidade.

6. Existe associação significante, no nível de 0,05, comparando o estado civil das clientes com quem elas residem.

7. Existe associação significante, no nível de 0,05, comparando o planejamento familiar e o não planejamento com a idade das clientes.

\section{REVISÃO DA LITERATURA}

The American College of Obstetricians and Ginecologists (1978) ao citar conceitos em Planejamento Familiar, diz:

“Afinalidade do planejamento familiar é ajudar os indivíduos à alcançar finalidades reprodutoras. As decisões a serem consideradas se referem à possibilidade de ter filhos, à oportunidade e intervalo entre os 
nascimentos e ao tamanho da família. O planejamento familiar eficazmente praticado se baseia em decisões inteligentemente esclarecidas e ação que permita reduzir a mortalidade e morbidade materna e infantil, nascimentos extraconjugais, nascimentos indesejáveis e distúrbios transmitidos geneticamente.'

\section{Práticas e Problemas da Concepção}

"Em toda a América Latina, importantes circunstâncias econômicas, sociais a culturais alteram de maneira considerável as aspirações do casal médio quanto ao número de filhos a ter.

O desejo de famílias pequenas dissemina-se atualmente por todos os países da região e a motivação para a pratica do planejamento familiar é, provavelmente, mais forte do que nunca. Em recentes pesquisas de fecundidade, quando indagadas sobre o número ideal de filhos que gostariam de ter, as mulheres do Peru responderam 2,7 em média, as da Colômbia e do Chile 2,8, as do Brasil 3,0 e as do México e República Dominicana 3,3. É provável, porém, que até mesmo esses baixos índices exagerem o número de filhos que os casais na verdade preferiam ter.

Em relação aos seus programas de planejamento familiar, a América Latina é geralmente mencionada como uma história de sucesso.

A maioria dos países da região adotou politicos oficiais favoráveis ao apoio governamental e privado aos serviços de planejamento familiar; os níveis de uso de contraceptivos em muitos países aumentaram substancialmente nos últimos 20 anos (deve-se observar em especial, em determinados países, o recurso à esterilização como métodos contraceptivos em idades cada vez mais baixas; e as taxas de natalidade apresentaram um expressivo declínio).

No total, o tamanho da família média na América Latina decresceu em torno de $45 \%$ desde o início da década de 1960 - de aproximadamente seis para pouco mais de três filhos por mulher.

Em resposta ao desejo generalizado de famílias menores, a prática de contracepção para evitar gravidez não desejada tornou-se comum em quase todos os países da região. De acordo com recentes pesquisas de fecundidade, muitos casais estão praticando o planejamento familiar com o objetivo de terem filhos quando as circunstâncias melhorarem, a podem parar de ter filhos quando tiverem tido todos os que desejavam. O grupo para o qual o planejamento familiar é mais proeminente compõem-se de mulheres em idade reprodutiva ( 15 a 44 anos) que já tiveram relações sexuais. Cerca de $70 \%$ das mulheres entre 15 e 44 anos sem todos os países enquadram-se nessa categoria. Portanto, cerca de $30 \%$ de 
mulheres de 15 anos ainda não tiveram uma união (legal ou consesual) e informam que nunca tiveram relações sexuais; as mulheres nessa categoria são, em sua maioria, menores de 20 anos". (The Alan Guttmacher Institute - 1994)

\section{METODOLOGIA}

\section{Amostra}

A amostra perfaz um total de 96 mulheres. Foram entrevistadas todas as mulheres que estavam em seus domicílios no momento da entrevista. Os locais para as entrevistas foram intensionalmente escolhidos para que fossem entrevistados das zonas sociais periféricas de Passo Fundo. As entrevistas foram realizadas com mulheres das vilas Zacchia, Victor Issler e Bairro São José que estavam em seus lares quando da entrevista.

\section{Instrumento}

O instrumento para a coleta de dados constitui-se num formulário (anexo I) que foi elaborado com base na literatura e na prática profissional, O formulário que constitui-se no instrumento de pesquisa é composto pelas variáveis estudadas. O formulário foi testado pela autora do mesmo e pelas acadêmicas de Enfermagem previamente treinadas. Foi realizado a seguir o plano piloto com o objetivo de completar o treinamento dos entrevistadores e testar o formulário empregado.

\section{Procedimentos}

A coleta de dados foi realizada mediante a aplicação de formulário elaborado com esta finalidade.

Foi preenchido em entrevista individual com as mulheres presentes em seus domicílios.

Foi mantido sigilo sobre a identidade das mulheres entrevistadas. As mulheres que participaram da entrevista foram orientadas sobre o trabalho que foi realizado, da importância e a seriedade do mesmo e da exatidão das respostas. 


\section{Resultados e Conclusões}

O tratamento estatístico e a análise dos dados foram efetuados a partir de porcentagem e das hipóteses estatísticas e teste de significância "Qui-Quadrado" no nível de 0,05 entre as variáveis dependentes e independentes.

\section{CONCLUSÃO}

As características da clientela residente em setores sociais periféricos, que demanda assistência em Planejamento Familiar, são as seguintes:

1. Idade: a clientela entrevistada encontra-se na faixa etária entre 15 e 44 anos num percentual de $82,29 \%$;

2. Religião: a grande maioria da clientela entrevistada refere ser da religião católica, num percentual de $92,71 \%$;

3. Gestações: a clientela entrevistada é na sua maioria composta por multigestas, num percentual de 58,33\%;

4. Paridade: a clientela entrevistada apresentou uma percentagem de $43,74 \%$ para a multíparas;

5. Abortamento: a maioria das mulheres entrevistadas não tiveram abortamento num percentual de $80,21 \%$ e $14,58 \%$ para um abortamento;

6. Cesária: uma percentagem de 37,50\% das clientes entrevistadas se submeteram pelo menos a uma cesária;

7. Prematuros: apenas $3,12 \%$ das mulheres entrevistadas tiveram partos prematuros;

8. Com quem residem: uma percentagem de $85,42 \%$ das mulheres entrevistadas residem com o companheiro;

9. Estado Civil: 66,67\% das mulheres entrevistadas são casadas;

10. Ocupação: uma percentagem $72,91 \%$ das mulheres entrevistadas são unicamente donas de casa;

11. Cor da pele: foi encontrado uma percentagem de $96,88 \%$ de mulheres de pele branca;

12. Escolaridade: as mulheres entrevistadas apresentaram uma baixa escolaridade com uma percentagem de $39,60 \%$ para primário incompleto e analfabetos;

13. Idade da menarca: a idade da menarca teve maior incidência entre 10 e 15 anos, com uma percentagem de 90,63\%;

14. Planejamento familiar: apenas $51,04 \%$ das mulheres entrevistadas referiram que fazem ou fizeram planejamento familiar; 
15. Usam contraceptivos: mais da metade das mulheres entrevistadas usam métodos contracepticos, numa porcentagem de 52,08\%;

16. Métodos contraceptivos mais usados: entre os métodos mais usados aparece a pílula (método hormonal) com 48,84\%;

17. Desejam aprender sobro métodos contraceptivos: apenas $34,32 \%$ das mulheres entrevistadas referiram querer aprender sobre métodos contraceptivos;

18. Local de aquisição de anticoncepcional: compram na farmacia $78,13 \%$ das mulheres entrevistadas;

19. Métodos conhecidos: não conhecem nenhum método $25,71 \%$, o método hormonal (pílula) é conhecida por $59,37 \%$ das clientes entrevistadas;

20. Aspectos que gostariam de aprender sobre métodos contraceptivos: apenas $17,71 \%$ das mulheres entrevistadas gostariam de aprender tudo sobre os métodos contraceptivos;

21. Quem deve orientar sobre planejamento familiar: o médico foi o profissional mais indicado como orientador sobre o planejamento familiar com uma porcentagem de 57,29\%;

22. Quem orientou sobre o método que usa: o médico foi o profissional mais citado com $64,58 \%$;

23. Motivos que as levaram a limitar o número de filhos: a situação econômica foi a mais citada com 4 I ,67\% e a saúde com 19,79\%;

24. Ligadura de trompas: quanto a estficirurgia $18,75 \%$ referira já se submeteram a ela;

25. Uso de cigarros: quanto ao hábito de usar 34,38\% das entrevistadas referiram que tem este costume;

26. Presença de varizes: quanto à presença de varizes $35,42 \%$ referiram que são acometidas desta patologia;

27. Quantos cigarros consome ao dia: Vinte mulheres ou seja 60,61 $\%$ fumam 20 cigarros por dia, das 33 mulheres que fumam;

28. Presença de hipertensão arterial: das mulheres entrevistadas $25 \%$ referiram que apresentam esta patologia;

29. Apresentam diabetes: apenas $4,16 \%$ das mulheres entrevistadas referiram ser portadoras de diabete;

30. Apresentam obesidade: apresentam obesidade 12,5\% das Mulheres entrevistadas.

Observa-se que as hipóteses de 1 à 11 foram confirmadas. Portanto, aceita-se que:

\section{H1}

1. Não existe associação significante, ao nível de 0,05 , comparando o hábito de fumar das clientes com a presença da hipertenção arterial; 
2. Não existe associação significante, ao nível de 0,05 , comparando o hábito de fumar das clientes com a presença de obesidade;

3. Não existe associação significante, no nível de 0,05 , comparando a idade das clientes com o hábito de fumar;

4. Não existe associação significante, no nível de 0,05 , comparando a idade das clientes com a presença da hipertenção arterial;

5. Não existe associação significante, no nível de 0,05 , comparando a idade das clientes com a presença da obesidade;

6. Não existe associação significante, no nível de 0,05 , comparamdo o estado civil das mulheres com quem elas vivem.

7. Não existe associação significante, no nível de 0,05 , comparando o planejamento familiar e o não planejamento com a idade das clientes.

\section{RECOMENDAÇÕES}

Conclui-se que os resutados obtidos nesta pesquisa são de grande utilidade como subsídios para o planejamento de ações da saúde da mulher dentro de uma nova e atual abordagem de assistência em planejamento familiar. Portanto, propõe-se:

1. Implementar programas de assistência integral à Saúde da Mulher, dando ênfase ao planejamento familiar;

2. Desenvolver programa com ênfase em ações educativas a nível ambulatorial;

3. Implementar as equipes multiprofissionais e interdisciplinar de modo a atender as necessidades de saúde e de planejamento familiar da clientela;

4. Estimular a integração docente, assistencial, envolvendo os cursos da área de Saúde da Universidade de Passo Fundo, a Secretaria de Saúde e Meio Ambiente e demais secretarias relacionadas com os problemas identificados;

5. Integrar as pessoas, família, e comunidade, objetos e sujeitos deste trabalho e dos programas de saúde;

6. Promover uma Campanha de Planejamento Familiar no município de Passo Fundo, visando motivar ainda mais a populaçãopara que esta procure os serviços de Planejamento Familiar já existente no município,

7. Desenvolver novas pesquisas na comunidade sobre planejamento familiar, ampliando assistir o conhecimento sobre as peculiaridades a clientela que demanda de assistência em planejamento familiar; 
8. Treinar pessoas auxiliar em planejamento familiar;

9. Oferecer à comunidade a oportunidade de participar de atividades em grupos específicos (Planejamento Familiar, adolescentes, climatéricas e pré-natal);

10. Diminuir o número de cesáreas e ligadura de trompas, mediante uma assistência adequada e educadora;

11. Dar à mulher condições para que ela escolha livremente seu método de planejamento familiar;

12. Que ao serem planejadas ações de planejamento familiar que se leve em conta a religião e o baixo grau de instrução da clientela;

13. Alertar as autoridades governamentais para que se reduza o número de mulheres desempregadas.

\section{REFERÊNCIAS BIBLIOGRÁFICAS}

1. ALDRINI, J. N. e BUENO, J. G. R.: Ginecologia e obstetrícia, vol. 11. $\mathrm{n}^{\circ}$ 3, mai/jun, 1991.

2. HARDY, E. E. et. al: Adequação do uso da pílula anticoncepcional entre mulheres unidas. Rev. Saúde Públ., São Paulo, 25(2):96-102, 1991.

3. MORETTI, Eleonor: Estudos de aspectos relacionados com o planejamento da grávidez e o estado civil da clinigesta. Passo Fundo, 1987.

4. NERY, M. E. da Silva e MORETTI, Eleonor: Levantamento das necessidades humanas básicas nas vilas Santa Marta, Issler. Luiza e Bairro São José. Passo Fundo, 1981-1983.

5. PLANEJAMENTO, Familiar Agora São Paulo, julho. ano X, $\mathrm{n}^{\circ} 249$, 1994.

6. THE ALAN GUTTMACHER INSTITUTE, 1994: Aborto clandestino: uma realidade latino-americana. Nova Iorque: The Alan Guttmacher Institute.

7. THE AMERICAN COLLEGE OF OBSTETRICIANS AND GINECOLOGISTS: Atualização obstétrica e ginecológica. Rio de Janeiro, Guanabara Koogan, 1978, p. 229. 


\section{Curso de Enfermagem e Obstetrícia Enfermagem Obstétrica}

\section{FICHA PARA COLETA DE DADOS}

\begin{tabular}{|l|l|l|l|l|l}
\hline 1 & 2 & 3 & 4 & 5 & 6 \\
\hline Data & Idade & Religião & Gesta & Para & Abortos \\
\hline
\end{tabular}

\begin{tabular}{|l|l|l|l}
\hline 7 & 8 & 9 & 10 \\
\hline Cesáreas & P. Normal & Prematuros & Procedência/Município \\
\hline
\end{tabular}

\begin{tabular}{|l|l|l}
\hline 11 & 12 & 13 \\
\hline Zona Rural/Urbana & $\begin{array}{l}\text { Residente com: } \\
\text { o companheiro ( ) } \\
\text { os pais () } \\
\text { Outros( ) }\end{array}$ & $\begin{array}{l}\text { Estado Civil: } \\
\text { solteira ( ) } \\
\text { casada ( ) } \\
\text { viúva ( ) } \\
\text { separada ( ) } \\
\text { desquitada () } \\
\text { divorciada ( ) }\end{array}$ \\
\hline
\end{tabular}

\begin{tabular}{|c|c|c|}
\hline 14 & 15 & 16 \\
\hline $\begin{array}{l}\text { Ocupação } \\
\text { dona de casa ( ) } \\
\text { empregada doméstica ( ) } \\
\text { outra - especificar ( ) } \\
\text { estudante ( ) }\end{array}$ & $\begin{array}{l}\text { Cor da Pcle } \\
\text { branca ( ) } \\
\text { preta ( ) } \\
\text { amarela ( ) } \\
\text { parda () }\end{array}$ & $\begin{array}{l}\text { Planeja a Familia } \\
\operatorname{sim}() \\
\text { não( ) }\end{array}$ \\
\hline
\end{tabular}

Escolaridade do Marido e da Mulher

Analfabeto ( )

Sabe ler e escrever ( )

Primário incompleto ( )

Ginâsio incompleto ( )

Ginásio completo ( )

Primário completo ( )

Primeiro grau incompleto ( )

Primeiro grau completo ( )
Colegial incompleto ( )

Colegial completo ( )

Segundo grau incompleto ()

Segundo grau completo ( )

Supcrior incompleto ( )

Superior completo ( )

Pós-graduado: especialista ( )

Mestre () 


\begin{tabular}{|l|l|l|}
\hline 18 & 19 & 20 \\
\hline Idade da menarca & Usa anticonceptivo & Deseja aprender MAC \\
\hline
\end{tabular}

\begin{tabular}{|l|l|}
\hline 21 & 22 \\
\hline Que aspecto gostaria de aprender? & Qual o método que a senhora usa? \\
\hline
\end{tabular}

\begin{tabular}{|l|l|}
\hline 23 & 24 \\
\hline Quais os M.A.C. que a senhora conhece? & Quem deveria orientar sobre o M.A.C. \\
& Médico () \\
Enfermeiro( ) & Familia( ) \\
Escola( ) \\
Farmácia( ) \\
Posto de Saúde( ) \\
Hospital ( ) \\
Posto LBA( ) \\
Outros( ) \\
(cspecilicar)
\end{tabular}

\begin{tabular}{|l|l|}
\hline 25 & 26 \\
\hline Quem recomendou o método que usa? & $\begin{array}{l}\text { Onde compra ou consegue o } \\
\text { anticoncepcional? }\end{array}$ \\
\hline
\end{tabular}

\begin{tabular}{|l|l}
\hline 27 & 28 \\
\hline $\begin{array}{l}\text { Quais os motivos para limitar o número } \\
\text { de filhos }\end{array}$ & Se fez esterilização \\
econômicos ( ) & Por que feź? \\
saúde ( ) & \\
idade ( ) & \\
trabalho dos pais () & \\
sem opiniño ( ) & \\
outros (especificar)( ) & \\
\hline
\end{tabular}

\begin{tabular}{|l|l|}
\hline 29 & 30 \\
\hline $\begin{array}{l}\text { Fuma } \\
\text { sim () }\end{array}$ & $\begin{array}{l}\text { Tem varizes } \\
\text { nim() } \\
\text { não () não () } \\
\text { Quantidade /dia } \quad \text { /dia }\end{array}$ \\
\hline
\end{tabular}

\begin{tabular}{|c|c|c|}
\hline 31 & 32 & 33 \\
\hline $\begin{array}{l}\text { Tem hipertenção } \\
\text { sim ( ) } \\
\text { não ( ) }\end{array}$ & $\begin{array}{l}\text { Tem obesidade } \\
\operatorname{sim}() \\
\text { não () }\end{array}$ & $\begin{array}{l}\text { Tem diabetc } \\
\operatorname{sim}() \\
\text { não () }\end{array}$ \\
\hline
\end{tabular}

